\title{
Can the basin morphology alone provide an insight into floodplain delineation?
}

\author{
S. Manfreda, A. Sole \& M. Fiorentino \\ Dipartimento di Ingegneria e Fisica dell'Ambiente, \\ Università degli Studi della Basilicata, Italy
}

\begin{abstract}
The present research was aimed to evaluate flooding exposure by exploiting the potential of morphological indices (e.g., drainage area, local slope, curvature, etc.). It was found that the areas exposed to flood inundation may be delineated quite well by adopting a modified topographic index computed from DEMs (Digital Elevation Models). Since the modified topographic index is sensitive to the spatial resolution of the digital elevation model, the scale dependence is investigated showing an increase in the performances of the method with the resolution of the DEMs. The procedure proposed is tested over the Arno river basin using the existing documentation on flooding exposure produced by the local River Basin Authorities. The use of the proposed modified topographic index may represent a useful and rapid tool in delineating the flood prone areas in ungauged basins and in areas where expensive and time consuming hydrological-hydraulic simulations are not possible.
\end{abstract}

Keywords: flooding areas, topographic index, digital elevation model (DEM).

\section{Introduction}

Planning and territorial management must take into account exposure to natural hazards in order to implement risk reduction programs for human life and public safety [8]. In this context, the delineation of the areas subject to flood inundations raises complex problems regarding the definition of hydrological forcing and the parametrization of models for flood wave propagation $[3,4,10]$.

The increasing availability of new technologies for the measurement of surface elevation (e.g., GPS, SAR interferometry, radar and laser altimetry) led to an increase in the attraction of DEM-based hydrogeomorphic models. As a 
consequence, more scientists are focusing on DEM-based automated procedures for the delineation of floodplains [2, 11]. These models aim at supplying automatic procedures for the delineation of areas exposed to flood inundation through a direct comparison between river stage and the elevation of the surrounding terrain. Other models offer more simplified procedures such as the one proposed by Oliveri et al. [7], where the definition of flood inundation areas is deduced from a fuzzy methodology based on two measurements: the local slope and the distance from the river.

In recent years, much effort has gone into the identification of flood prone areas through the use of hydrological and hydraulic studies carried out by River Basin Authorities (public institutions dedicated to river basins management). These studies include topographic surveys and numerical modelling for the flood wave propagation. Manfreda et al. [6] have recently used the technical documentation, produced during the definition of Hydrogeological Management Plan (PAI) by the River Basin Authorities, to define a synthetic procedure for flood inundation exposure delineation.

The development of simplified methodologies is taken further in the present study to investigate the relationship between areas exposed to flood inundation and the geomorphologic characteristics of the terrain (contributing area, local slope of the surface, curvature, topographical index) showing a strong correlation with the topographic index [5]. Manfreda et al. [6] defined a new expression of the topographical index more suited to the task of delineating flood exposure directly from a DEM analysis. This permitted the definition of a fast procedure for the calculation of flood inundation areas using a threshold level to discriminate between areas exposed to flood inundation and non exposed areas. The objective of the study is to estimate the optimal threshold level for the identification of flood prone areas and the scale dependence of the method.

The work is divided in three parts: the first contains information regarding the hydrological-hydraulic study adopted, secondly areas exposed to flooding were analysed to evaluate the geomorphological characteristics of areas exposed to flooding and non exposed and lastly a procedure is put forward for the delineation of the areas most exposed to flooding, evaluating also the scale dependence of the methodology. The analyses were carried out using a digital terrain model obtained through interferometric data gathered by the space shuttle campaign by NASA with a cell-size of $90 \mathrm{~m}$ (CGIAR-CSI: http://srtm.csi.cgiar.org/).

\section{Identification of flood prone areas carried out by river basin authorities}

In Italy, the Environmental Protection Law 183/1989 identified hydrographic basins as the optimal physical environment for land management in terms of risk limitation as well as for a sustainable utilization of water resources. On this basis, the River Basin Authorities organized their policy through a programme of actions (constraints and directives) aimed at the achievement of physical 
conditions of the river basins compatible with hydraulic safety, the use of water resources, land use, and the protection of natural ecosystems.

In several cases, the cartography of the flood prone areas was made available by the River Basin Authorities. Among others, the study carried out on the Arno River was one of the most detailed available over the Italian territory and hence most useful for our purposes.

\subsection{The Arno river basin}

The Arno is one of the biggest Italian rivers that covers a territory of about 8830 $\mathrm{km}^{2}$. Several hydrologic/hydraulic studies have been made over this area contributing to the development of the PAI (Hydrogeological Asset Plan available on the web page http://www.arno.autoritadibacino.it/). On the basis of these studies, it is possible to observe that different exposure levels are defined in terms of different return period of the flood event as well as possible values of the water depth in a given location. Specifically, the flood exposure over the basin is graded in the following way: $i$ ) very high flood exposure (P4); $i$ ) high flood exposure (P3); iii) average flood exposure (P2); iv) moderate flood exposure (P1) and no-flood exposure (P0). Areas with stagnant water are also reported in the same map of flood exposure (see Figure 1(A)). For the scope of the paper, we will consider areas exposed to flood inundation risk to be the ensemble of areas given above including water bodies and stagnant water areas as well. This implies that the delineation of flooding areas will refer to the higher return period $(\mathrm{Tr}=500$ years).

Flood exposure map over the entire Arno is depicted in Figure 1 along with some geomorphological characteristics of the basin such as: digital elevation model (DEM), logarithm of the drained area per unit contour length $\left(\log \left(a_{d}\right)\right)$, local slope, curvature, and topographic index. These maps provide a general description of the marked spatial variability of the basin's geomorphological characteristics. The elaborations have been carried out in Matlab exploiting the algorithm proposed by Schwanghart [9] to compute the multiple flowdirection and the flowaccumulation.

\section{Flood inundation exposure and geomorphological characteristics of the terrain}

The cartography produced by the River Basin Authority of the Arno River has proven to be a useful tool in the investigation of the geomorphological influence on flood inundation exposure. There are essentially two scientific questions posed here: $i$ ) Are there geomorphological signatures useful for the delineation of flood prone areas? ii) What is the optimal scale to describe such characteristics?

These questions can be answered through an examination of the factors which have greatest impact on the diffusion of a flood wave including: slope, upslope area in a point, surface concavity and topographic index. For the Arno River Basin, these measurements were computed adopting a DEM with a cell-size 
PAl of the Arno River

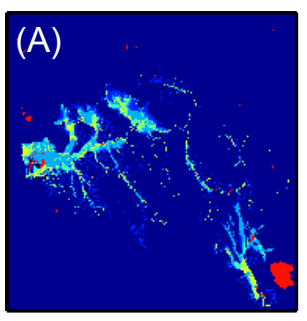

$\log \left(a_{c}\right)$
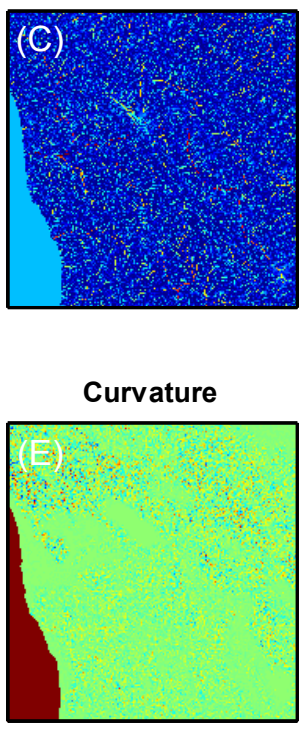
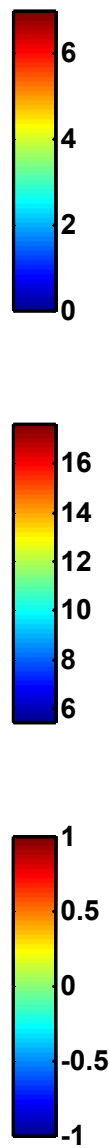
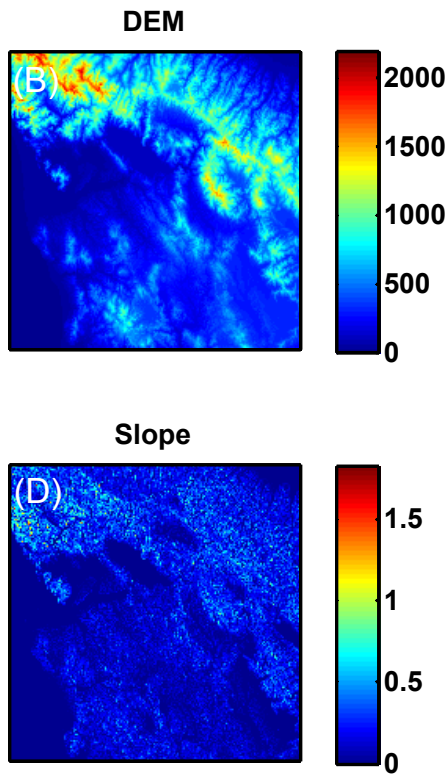

\section{Topographic index}

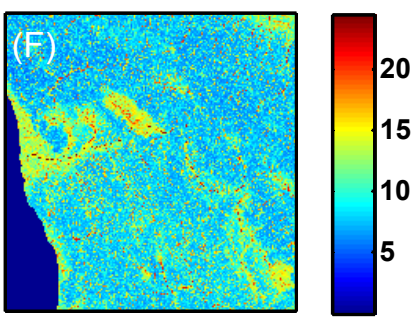

Figure 1: Description of the study area and its characteristics: (A) flood inundation exposure map of the Arno river basin where different codes correspond to different flood exposure levels $(1=\mathrm{P} 1 ; 2=\mathrm{P} 2$; $3=\mathrm{P} 3 ; 4=\mathrm{P} 4 ; 5=$ stagnant water, and $6=$ water bodies); (B) DEM; (C) $\log \left(a_{d}\right)$ where $a_{d}$ is drained area per unit contour length; (D) surface local slope; (E) surface curvature; (F) topographic index proposed by Kirkby [5].

resolution of $90 \mathrm{~m}$ highlighting their influence on the areas exposed to flood inundation.

The geomorphological characteristics of the areas exposed and non-exposed to flood inundation have been investigated through the probability distribution of the quoted geomorphological characteristics conditioned on the flood inundation exposure in Figure 2. The different distributions can be reclassified, without information loss, into two categories according to whether an area is exposed to flood inundation or not. Actually, the conditioned probability distributions of the 
different geomorphological measurements at the 4 exposure levels (P1, P2, P3, $\mathrm{P} 4)$ show very similar shapes and are very different from the one conditioned on P0 (areas non exposed to flood inundation).
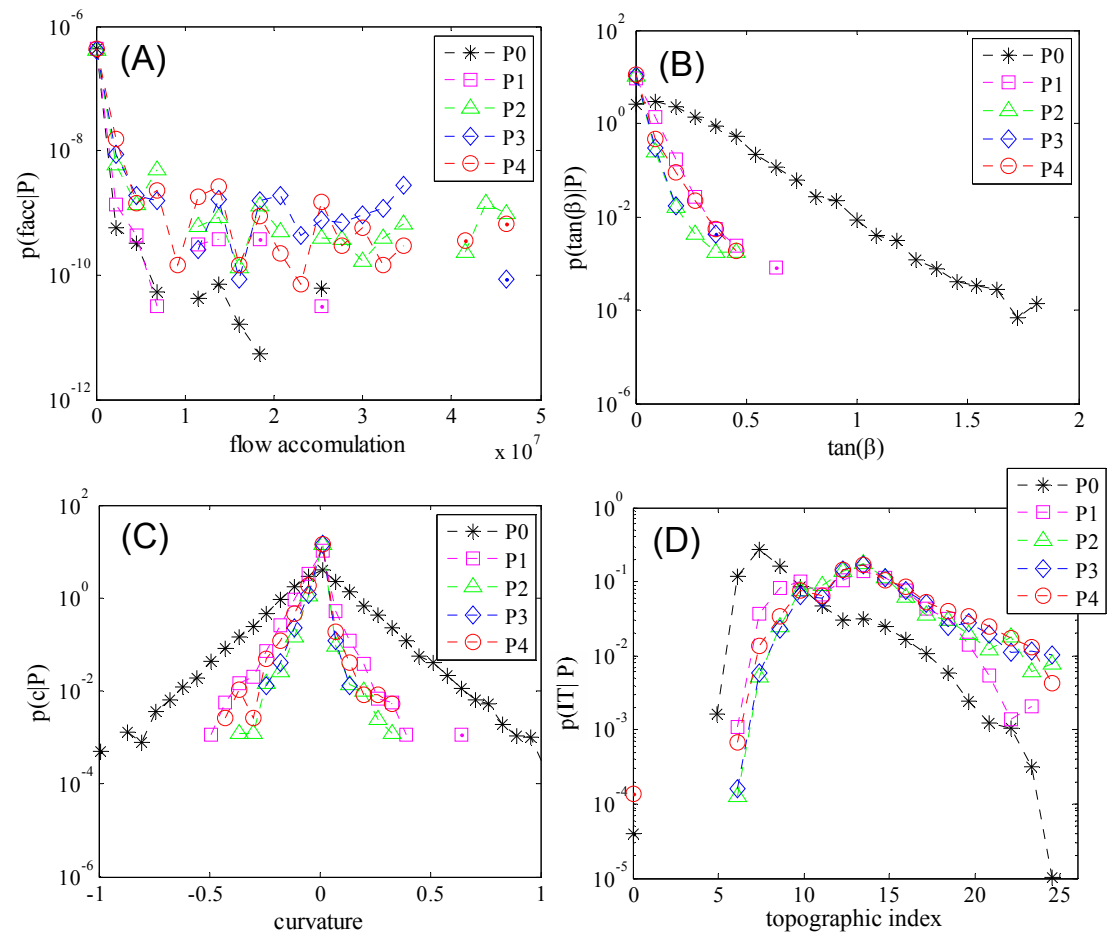

Figure 2: $\quad$ Probability distribution of the geomorphological characteristics of the terrain conditional on the flood exposure plotted in semilogarithmic scale: (A) flow accumulation; (B) slope; (C) curvature; (D) topographic index.

Figure 2 highlights the marked geomorphological differences between flood prone areas and non exposed areas. In general, the areas exposed to flood inundation show values of flow accumulation variable in wide interval, reduced local slope, curvature contained in a narrow interval close to zero and high topographic index. Amongst all the variables taken into consideration, the local slope and the topographic index show the most marked dependency on the flood inundation exposure.

The topographic index includes two representative measurements one relating to the structure of the hydrographic basin, the drainage area per unit contour length, and one to the presence or absence of flat surface (slope). Given the characteristics of the index which is well correlated with the areas where meteoric water tends to accumulate, it is likely that this is also indicative of areas most exposed to flood inundation. 


\section{The delineation of areas exposed to flooding by means of a modified topographic index}

The topographic index (IT) has proven to be strongly related to the areas exposed to flood inundation. Its performance has been improved introducing a new topographic index that from now on will be referred as modified topographic index $\left(I T_{m}\right)$. The modified topographic index takes the form

$$
I T_{m}=\ln \left(a_{d}^{n} / \tan (\beta)\right),
$$

where $a_{d}[\mathrm{~m}]$ is the drained area per unit contour length, $\tan (\beta)[-]$ is the local slope and $n$ is an exponent $\leq 1$.

The modified topographic index allows the delineation of the portion of a basin exposed to flood inundation assuming as exposed to flood inundation all the areas characterised by a modified topographic index exceeding a given threshold, $I T_{m s}$. The threshold $I T_{m s}$ was estimated on the basis of the flooding area reported in the PAI of the Arno River Basin. For this purpose, two error functions were defined

$$
\begin{gathered}
E R 1=\frac{\text { Flooding areas with } I T_{m} \leq I T_{m s}}{\text { Flooding areas from } P A I} 100, \\
E R 2=\frac{\text { Non Flooding areas with } I T_{m} \geq I T_{m s}}{\text { Non Flooding areas from } P A I} 100 .
\end{gathered}
$$

The error ERI defines the percentage of error in relation to the correct identification of flooding areas while ER2 represents the error due to the overestimation of the method. It should be remarked that a reduction in the value $I T_{m s}$ generally produces an overestimation of the flood inundation area and an increasing reduction in ER1. The objective was to define a threshold value which minimizes both errors in the delineation of the flood inundation areas. It is important to bear in mind that the relative weight of the two indices is not the same. Rather the two denominators are different creating a greater relative weight of ER1 with respect to ER2.

The value of the exponent $n$ was defined through a minimization of the error function given by the sum of $E R 1$ and $E R 2$, with a variation in the threshold value of $I T_{m s}$. The results obtained in the case of the Arno show that the error function reaches a minimum when the exponent $n$ is equal to 0.15 ; while the optimal threshold value, with a cell resolution of $90 \mathrm{~m}$, is $I T_{m s}=3.90$.

\subsection{The scale dependence of the modified topographic index}

The spatial distribution of the topographic index is inevitably linked to the cellsize of the adopted DEM [12, 13]. This dependence is investigated comparing the errors ER1 and ER2 obtained using the topographic index by Kirkby and its modified version $\left(I T_{m}\right)$ computed from DEMs with different cell-size.

The scale dependence analyses were carried starting from a digital elevation model with cell-size of $90 \mathrm{~m}$. From this model, DEMs with different resolution were obtained through aggregations of the first and intermediate hydrological elaborations for the construction of the topographic index and modified 
topographic index. It is worthwhile to emphasize that, although the indices were obtained with scales different from the initial dimensions of $90 \mathrm{~m}$, the calculation of errors was however carried out using grids reconverted to the $90 \mathrm{~m}$ to avoid the influence of the aggregation processes in the error calculation.
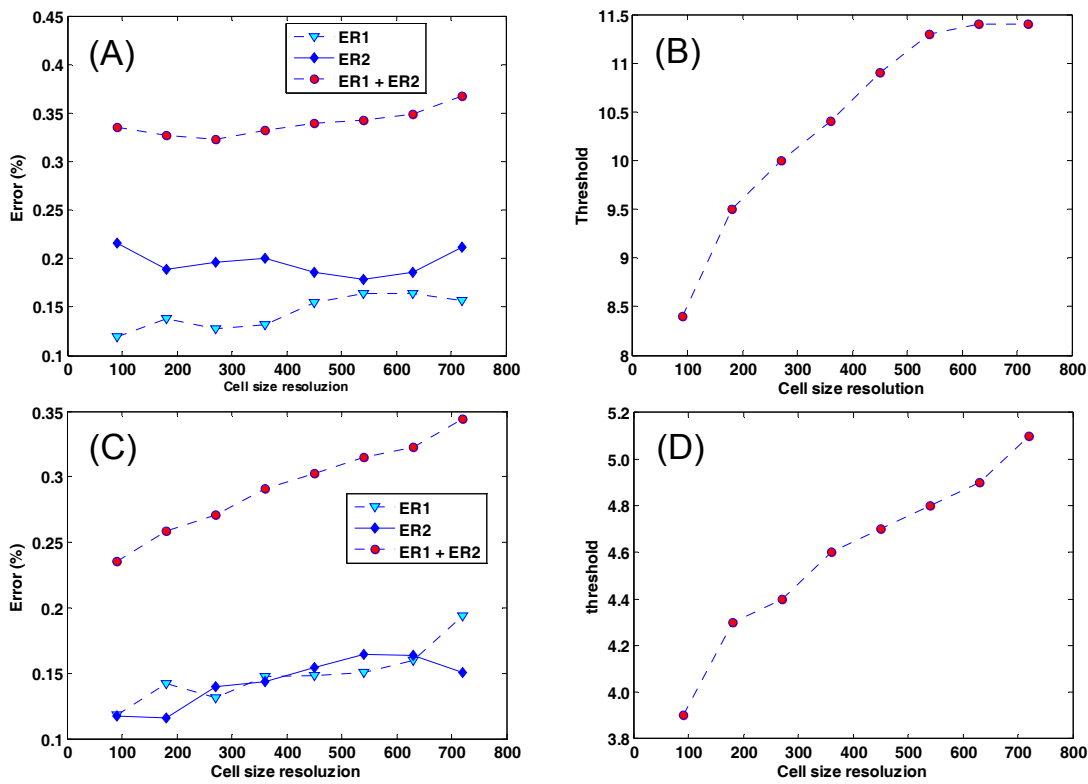

Figure 3: Changes in the errors functions (A) and (C) and in the thresholds value with the reference scale of the DEM (B) and (D) obtained adopting the topographic index in $\mathrm{A}$ and $\mathrm{B}$ and adopting the modified topographic index in C and D.

By applying a query that selects all the areas with topographic index higher than a given threshold value $\left(I T_{m} \geq I T_{m s}\right)$, it is possible to delineate a portion of the basin with given characteristics. For each reference scale, this area was compared with those exposed to flood inundation leading to an error expressed as a function of the adopted reference scale. Parallel to this, for each scale, an evaluation of the threshold value which minimized the sum ER1 $+E R 2$ was carried out (Figure 3(A) and (B)).

Using the topographic index by Kirkby [5], it is possible to obtain a map that approximates that of the areas exposed to flood inundation with a total error of about $32 \%$ in correspondence of a cell-size resolution of $270 \mathrm{~m}$. This result is due to the opposite tendency observed in the error indices ERI and ER2 with the change in the cell-size. Moreover, the total error showed a slight changes with the change in scale, while the threshold reference value was markedly influenced by the cell-size. 
Similar analyses to those discussed above were carried out regarding the modified topographic index providing however very different results (see Figure 3(C) and (D)). Specifically, it was observed that the total error $(E R 1+E R 2)$ was lower than the previous case and it was more influenced by the cell-size of the DEM. In this case, the minimum error value occurred with the maximum DEM resolution (cell-size of $90 \mathrm{~m}$ ). Thus, it is likely that the error could be further reduced by using digital elevation models of higher resolution. The threshold value for the modified topographic index with the lowest total minimum error was 3.90 .

\section{Results of the synthetic method}

The modified topographic index allowed an improvement in the description of areas exposed to flood inundation as one can see in Figure 4, which shows a comparison between the flooding areas defined by the PAI of the Arno Basin Authority, the areas with a topographic index of IT>8.40 (obtained using DEM with resolution of $90 \mathrm{~m}$ ) and the areas with a modified topographic index $I T_{m}>3.90$ (obtained using DEM with resolution of $90 \mathrm{~m}$ ). The comparison shows a sharp visible improvement with the modified topographic index calculated starting from a DEM with a resolution of $90 \mathrm{~m}$ (the highest available). This last result is even more clear in the distribution of errors obtained comparing the PAI map with those obtained through the synthetic method, using both the topographic and the modified topographic index, where the underestimation error are associated with the value 1 and overestimation with -1 (Figure 4(C) and (E)). It should be pointed out that the comparison was made between surfaces belonging to the watershed of the Arno River given the availability of flood inundation maps obtained from calculations carried out using hydraulichydrologic models applied at the basin scale.

In order to validate the outcomes of the present research, the same methodology has been applied over different areas of the Italian territory where a description of the areas exposed to flooding was also available. The method provided a good representation of the areas most exposed to flood inundation also in these cases that are not reported herein for sake of brevity.

\section{Conclusions}

The methodology proposed for the delineation of areas exposed to flooding offers an estimation of the flooded areas with a very low underestimation and a more relevant overestimation. This may be due to terrain characteristics and to protective measures which cover conspicuous portions of the territory otherwise subject to flooding. The geomorphological method described here is a valid preliminary tool in contexts where there is a lack of data for detailed hydrologic and hydraulic simulations and in those areas which lack of serious hydraulic protective measures.

The methodology may benefit from the use of a higher resolution DEM as one may expect by analysing Figure 4 . The errors associated with different scales 
are deeply influenced by the grid cell resolution and tend to decrease when using a more detailed description of the topography. It is also necessary to remark that the threshold values of $I T_{m s}$ were found to vary with the reference scale.
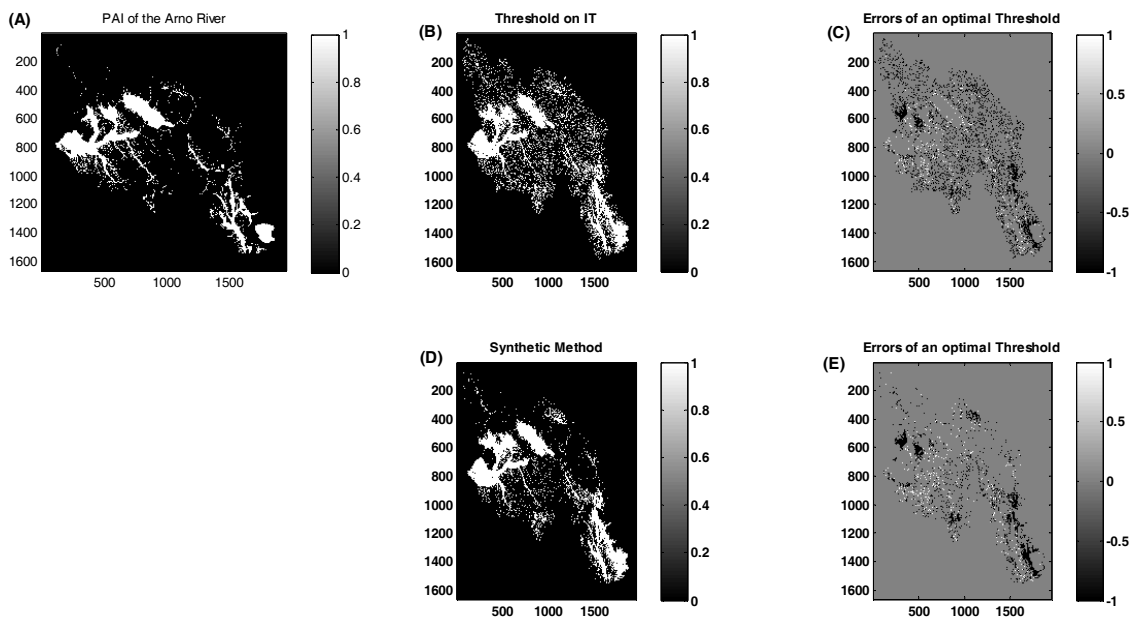

Figure 4: Comparison between: (A) the areas exposed to flood inundation according to the PAI of the Arno River Basin Authority; (B) the map of areas with topographic index superior to a threshold value of 8.40; (C) error distribution given by the difference between the map A and B; (D) map of areas with modified topographic index superior to the threshold value of 3.90; (E) error distribution given by the difference between the map A and D.

It is evident from the studies carried out over this area and other case studies that the modified topographic index functions much better in areas with a more marked topography than in extremely flat lands where, inevitably the index tends to have higher values [6]. Further studies are needed regarding the use of the methodology possibly in areas where detailed information on flood inundation exposure are available in order to optimize the estimation of threshold values and define the optimal scale of representation of the modified topographic index to minimize the underestimation-overestimation errors. In the present study, a DEM with a cell-size lower than $90 \mathrm{~m}$ over such a large basin was not available, but the same methodology will be applied in further applications over a smaller river basin where a detailed DEM is available.

\section{Acknowledgement}

S.M. would like to thank the Fondazione Carical for the economic support provided for his research activities. 


\section{References}

[1] CGIAR Consortium for Spatial Information (CGIAR-CSI), SRTM 90m Digital Elevation Data Online. http://srtm.csi.cgiar.org/

[2] Gallant, J.C., \&Dowling, T.I., A multiresolution index of valley bottom flatness for mapping depositional areas. Water Resources Research, 39(12), 1347, 2003.

[3] Horritt, M.S. \& Bates, P.D., Evaluation of 1D and 2D numerical models for predicting river flood inundation, Journal of Hydrology, 268(1-4), 87-99, 2002.

[4] Horritt, M.S., Calibration and validation of a 2-dimensional finite element flood flow model using satellite radar imagery. Water Resources Research, 36(11), 3279-3291, 2000.

[5] Kirkby, M.J., Hydrograph modelling strategies, in: Progress in Physical and Human Geography. edited by: R.F. Peel, M.D. Chisholm, and P. Haggett, Heinemann, London, 69-90, 1975.

[6] Manfreda, S., Sole, A., Fiorentino, M., Valutazione del pericolo di allagamento sul territorio nazionale mediante un approccio di tipo geomorfologico (In Italian). L'Acqua, 4, 43-54, 2007.

[7] Oliveri, E., Noto, L., Calabrò, P., Metodologie semplificate per la delimitazione di aree a rischio di inondazione (In Italian). Proc. of "XXVI Convegno di Idraulica e Costruzioni Idrauliche”, Catania, 1998.

[8] Petak, W.J., Emergency Management: A Challenge for Public Administration. Public Administration Review 45, 3-7, 1985.

[9] Schwanghart, W., Robust flow accumulation. Mathworks File-Exchange, 2007. http://www.mathworks.com/matlabcentral/

[10] Werner, M.G.F., Hunter, N.M. and Bates, P.D., Identifiability of distributed floodplain roughness values in flood extent estimation. Journal of Hydrology 314(1-4), 139-157, 2005.

[11] Williams, W.A., Jensen, M.E., Winne, J.C., Redmond, R.L., An Automated Technique for Delineating and Characterizing Valley-Bottom Settings. Environmental Monitoring and Assessment, 64(1), 105-114, 2000.

[12] Wolock, D.M., Price, C.V., Effects of digital elevation model map scale and data resolution on a topography-based watershed model. Water Resources Research, 30(11), 3041-3052, 1994.

[13] Zhang, W., Montgomery, D.R., Digital elevation model grid size, landscape representation, and hydrologic simulations. Water Resources Research, 30(4), 1019-1028, 1994. 